\title{
UMA CONCEPCÃO DIALÉTICA DAARTE A PARTIR DA GÊNESE DO CONCEITO DE TRABALHO NA FENOMENOLOGIA DO ESPÍRITO DE HEGEL ${ }^{1}$
}

\author{
Márcia Gonçalves ${ }^{2}$ \\ marciacfgoncalves@superig.com.br
}

\begin{abstract}
RESUMO A Fenomenologia do Espírito de Hegel não é ainda o lugar específico da posição de sua filosofia da arte propriamente dita. Entretanto, é possível compreender a relação sistemática entre alguns conceitos fundamentais desta obra de 1807 e a concepção hegeliana de arte da maturidade. A partir desta relação, destacaremos em nossa interpretação três diferentes e complementares teses: 1. Da obra de arte como produto ideal do trabalho do espírito (Geist); 2. Do simbolismo da religião natural como produto do trabalho do artesão à beleza da religião da arte; 3. Da necessidade do oráculo à subjetividade concreta do ator de teatro.
\end{abstract}

Palavras-Chave Hegel, Fenomenologia, Arte

ABSTRACT Hegel's Phenomenology of Mind is not the specific place of the position of his philosophy of arts. However, it is possible to understand the systematic relationship between many fundamental concepts of this work of 1807 and the Hegel's conception of art in his maturity. Through this

1 Este artigo foi elaborado a partir da conferência proferida durante o "I Congresso Internacional de Filosofia da Sociedade Hegel Brasileira", realizado na Universidade Católica de Pernambuco.

2 Professora Adjunta do Departamento de Filosofia da Universidade do Estado do Rio de Janeiro. Artigo recebido em 15/09/05 e aprovado em 15/11/05.

KRITERION, Belo Horizonte, ${ }^{\circ}$ 112, Dez/2005, p. 260-272 
relationship, we will detach in our interpretation three different and complementary theses: 1. From the work of art as ideal product of the work of the "Geist"; 2. The symbolism of the natural religion as product of the worker to the beauty of the religion of the arts; 3 . The necessity of the oracle to the concrete subjectivity of the actor of the theatre.

Keywords Hegel, Phenomenology, Art

Embora a Fenomenologia do Espírito de Hegel não possua nenhum capítulo exclusivamente dedicado à arte, mas apenas um sobre a Religião da Arte, isto não nos autoriza a acreditar que a arte - e em especial a arte poética — não represente nenhum papel significativo nesta obra. Ao contrário, esta última foi comparada pelo próprio Hegel com uma das mais importantes obras de arte poéticas de todos os tempos: A Odisséia de Homero. O longo caminho do Espírito em busca de seu autoconhecimento, a partir de seu estranhamento e alienação ou perda de si até seu retorno a si mesmo, é semelhante à perda e retorno de Odisseu.

Esta analogia entre a Fenomenologia do Espírito e uma "epopéia absoluta", parte de uma idéia de Schelling, expressa em uma importante passagem de seu Sistema do Idealismo Transcendental que diz:

O que nós denominamos de natureza é um poema, oculto em letras secretas e maravilhosas. Pudesse o enigma revelar-se, reconheceríamos nisto a odisséia do espírito, que, maravilhosamente iludido, buscando a si mesmo, foge de si mesmo. ${ }^{3}$

O enigma do espírito desvendado por Hegel em sua Fenomenologia não emerge entretanto como revelação da natureza, tal como almejava Schelling, mas mostra-se no próprio desencadear da secular História da humanidade. Em suas Preleções sobre a Estética, ao discutir a possibilidade de uma odisséia do espírito enquanto representação artística, Hegel esclarece que aquilo que ele denomina de "epopéia absoluta" do espírito só pode ser afirmada como especulação filosófica propriamente dita, a qual suprassume por completo qualquer representação artística meramente intuitiva. A Fenomenologia do Espírito de Hegel realiza esta especulação, enquanto descrição do movimento

3 SCHELLING, Friedrich Wilhelm Joseph. System des Transzendentalen Idealismus (1800). In: SCHELLING, F. W. J.: Ausgewahlte Schriften: in 6 Bänden. Frankfurt am Main: Suhrkamp, 1985. p. 696. v. I. 
dialético de evolução do espírito no mundo em direção ao saber absoluto de si mesmo ou à consciência absoluta da idéia, atingindo a síntese entre o conceito aparentemente metafísico de espírito - que expressa a liberdade essencialmente necessária do ser que é para si - e a realidade imediatamente fenomênica da história do mundo - que expressa a necessidade aparentemente contingente do tempo:

(...) a mais elevada ação do espírito seria a história mundial mesma, e poder-se-ia querer elaborar este ato universal sobre o campo de batalha do espírito universal como a epopéia absoluta, cujo herói seria o espírito do homem, o "humanus", que se eleva e se educa, partindo da obscuridade da consciência, em direção à história mundial. Obviamente, exatamente por causa de sua universalidade, é que este conteúdo seria muito pouco individualizável para a arte. ${ }^{4}$

Nesta passagem Hegel justifica a inadequação entre a forma de expressão artística e o conteúdo absoluto da filosofia a partir da própria limitação dessa forma, que necessita sempre do recurso da individualização. $\mathrm{O}$ absoluto pode ser expresso através da obra de arte no máximo como figuras das divindades individualizadas, mas nunca em seu aspecto universal absoluto, o qual, segundo Hegel, só pode ser pensado e expresso através da linguagem do conceito. Esta linguagem do conceito, racional, ou melhor, espiritual, recorre, entretanto, muitas vezes, à descrição de inúmeras figuras concretas do próprio espírito, para esclarecer seu movimento dialético. E a arte, sendo ela mesma manifestação concreta do espírito em sua absolutidade, ou, como nos esclarece o próprio Hegel em sua Enciclopédia das Ciências Filosóficas em Compêndio, sendo uma das "esferas do espírito absoluto", é recorrentemente citada ao longo da Fenomenologia.

A principal recorrência dessa citação está diretamente relacionada com a idéia de obra de arte ou ainda com a idéia da arte como processo resultante de um fazer espiritual, ou melhor, de um trabalho do próprio espírito. Em outras palavras, a arte pode ser reconhecida como um dos temas centrais na Fenomenologia do Espírito, desde que não busquemos nela simples referências a obras históricas, ou mesmo uma espécie de fenomenologia da arte, mas sim que reconheçamos a arte como o último e mais elevado estágio do processo de formação e auto-reconhecimento implícitos no conceito hegeliano de trabalho.

A concepção hegeliana de trabalho que emerge de forma paradigmática na Fenomenologia do Espírito e que será alvo de inúmeros comentários,

4 HEGEL, G. W. F. Vorlesungen über die Ästhetik. (v. III). In: HEGEL, G. W. F.: Werke. Frankfurt am Main: Surkamp, 1986. p. 356, v. 15. (A seguir, citado apenas como Ästhetik). 
inclusive de seu reconhecimento por parte de Marx como um dos mais importantes conceitos de Hegel, nem sempre é compreendida até seu desdobramento estético. Eu proponho aqui pensarmos esta relação como forma de compreensão da ausência de um capítulo na Fenomenologia exclusivamente destinado à arte.

\section{1 - A obra de arte como produto ideal do trabalho do espírito}

Nos Manuscritos Econômico-Filosóficos, de 1844, Marx reconhece o conceito hegeliano de trabalho como uma das mais importantes contribuições do idealismo de Hegel e talvez como um dos mais importantes conceitos filosóficos de todos os tempos, o qual, por si só, justifica a leitura da Fenomenologia do Espírito. A importância atribuída por Marx a este conceito deve-se exatamente ao reconhecimento do aspecto extremamente materialista, realista e, sobretudo, dialético de sua concepção:

O grandioso na 'Fenomenologia' hegeliana está no fato de que [nela] Hegel compreende a auto-geração do homem como um processo; a concreção como oposição; a alienação como suprassunção da alienação; enfim pelo fato de que ele compreende a essência do trabalho e concebe o homem objetivo, verdadeiro - porque real - como resultado de seu próprio trabalho. ${ }^{5}$

A concepção hegeliana de trabalho está, como bem interpretou Marx, diretamente ligada à idéia de produção ou formação de si através da produção ou formação de uma objetividade que se revela, ao mesmo tempo, conservando nela a subjetividade daquele que a gerou. Esta alteridade que conserva a propriedade subjetiva do agente do trabalho que a formou é denominada por Hegel de propriedade. Este conceito, ao contrário de indicar um simples bem de consumo, significa a superação da relação meramente negativa com a objetividade em sua imediatidade natural, exatamente porque a formação através do trabalho, ao lapidar e aplainar a resistência natural da exterioridade imediata, nega da objetividade apenas a sua negatividade, ou seja, seu aspecto de alteridade. A propriedade atende não mais o desejo natural de consumo, mas a satisfação já espiritual de reconhecimento de si através da obra:

5 Tradução minha. No original: „Das Große an der Hegelschen ,Phänomenologie' ist also einmal, daß Hegel die Selbsterzeugung des Menschen als ein Prozeß faßt, die Vergegenständlichung als Entgegenständlichung, die Entäußerung als Aufhebung dieser Entäußerung; daß er also das Wesen der Arbeit faßt und den gegenständlichen Menschen, wahren, weil wirklichen Menschen, als Resultat seiner eigenen Arbeit begreift". C.f Ökonomische-philosophische Manuskripte aus dem Jahre 1844. In: MARX, Karl; ENGELS, Friedrich. Werke. Berlin: Dietz Verlag, Berlin (DDR), 1968. p. 547. Erste Teil. 
O homem, porém, (...) tem necessidades (Bedürfnisse) e desejos (Wünsche), cuja satisfação a natureza não é capaz de atingir imediatamente. Nestes casos, ele precisa conquistar a necessária auto-satisfação através de sua própria atividade; ele precisa se apossar (in Besitz nehmen) das coisas naturais, prepará-las, formá-las, lapidar toda a resistência (ou obstáculo) (Hinderliche) através da habilidade adquirida, e assim transformar o exterior em um meio, através do qual ele pode realizar-se, de acordo com todos os seus fins. ${ }^{6}$

Quanto mais espiritualidade contiver a obra, ou melhor, quanto mais espiritual for o trabalho de formação que a produz, maior será este reconhecimento, não apenas na intensidade de seu poder e profundidade, mas na amplitude de seu alcance coletivo. Hegel descobre, assim, uma hierarquia das obras humanas, de acordo com o grau de sua espiritualidade ou de sua capacidade de promover o reconhecimento do espírito não apenas subjetivo, mas do espírito em sua universalidade. Esta hierarquia diz respeito a um processo evolutivo de autoformação do próprio espírito humano, um processo que, segundo Hegel, parte de um impulso espontâneo e próprio da natureza humana de conferir ao mundo exterior o aspecto de uma realidade exteriorizada a partir de si mesmo. Essa realidade exterior perde, por meio da atividade prática do homem, seu imediato aspecto de independência ou resistência, perde o caráter de uma realidade em si, de uma necessidade puramente exterior ou contingente, para tornar-se meio para um fim mais elevado, que é o homem em sua espiritualidade. Em outras palavras: o homem só se torna fim em si mesmo, espírito, à medida que transforma o mundo objetivo em um meio secundário para sua própria existência. No mundo cultural, a objetividade do mundo real já se encontra subjetivada, espiritualizada, humanizada, perdendo assim o caráter de uma exterioridade estranha.

Essa visão hegeliana evolutiva de um processo de elevação espontâneo e necessário do espírito sobre a imediatidade natural implica a espiritualização ou subjetivação gradual da própria relação sujeito-objeto como parâmetro de evolução cultural ou de absolutização do espírito. Isso significa que, para Hegel, a relação homem-natureza atinge, pouco a pouco, formas de negação ou de superação mais avançadas culturalmente, ou seja, mais espiritualizadas. Isso consiste propriamente no que Hegel denomina "idealização da natureza" pelo espírito. Para Hegel, a forma mais elevada ou mais espiritualizada desta negação, ou seja, a forma mais efetiva de idealização do sensível encontrase na obra de arte, posto que a arte constitui já a primeira das esferas do espírito absoluto:

6 HEGEL. Ästhetik, v. I, p. 332. 
O primeiro impulso da criança já carrega em si esta transformação prática das coisas exteriores. O menino joga pedras no rio e admira os círculos que se formam na água, como uma obra, na qual ele ganha a intuição do seu ser próprio (des Seinigen). Esta necessidade (Bedürfnis) prossegue através de múltiplas aparições, até alcançar a forma da produção de si mesmo nas coisas exteriores, como é o caso da obra de arte. ${ }^{7}$

Não é por acaso que no parágrafo imediatamente anterior ao capítulo sobre o Espírito Hegel discute a relação entre a individualidade e a obra (das Werke). Sua intenção é mostrar como é possível distinguir uma forma de obra que sustenta a contradição interna entre o agir ou o trabalho que a produziu, ou o meio através do qual ela surgiu e a vontade que a gerou ou a sua finalidade, de uma verdadeira obra, ou da verdade da obra enquanto suprassunção de sua contradição própria, que consiste na unidade entre fazer e ser, querer e implementar, ou entre conceito e realidade. A realização desta síntese é descrita por Hegel como a transformação da própria concepção da obra de algo que desvanece para algo que permanece, enquanto Coisa mesma (Sache), que, ao contrário da mera coisa (Ding), é a "expressão do espiritual", uma objetividade não alienada de sua origem auto-consciente, e, conseqüentemente, livre, autêntica e universal. Esta obra verdadeira e universal, produto do trabalho de uma individualidade não mais singular, mas de uma espiritualidade em sua dimensão genérica e coletiva, revela-se originariamente como a substancialidade ou efetividade ética, historicamente manifesta no mundo grego, que produziu as obras de arte clássicas verdadeiramente belas.

A diferença entre a verdadeira obra de arte bela e a obra enquanto resultado de um trabalho ainda prosaico pode ser compreendida por meio da diferença de seus graus de espiritualidade ou, para usarmos uma expressão mais concreta, da diferença dos estágios de desenvolvimento cultural e ético do povo que as produziu. Esta evolução espiritual da obra não cessa com a realização da arte, mas a penetra e a perpassa, diferenciando os vários tipos de obra de arte. Uma das principais teses de Hegel para descrever este processo diz respeito à idéia de uma evolução da forma do divino em direção a manifestações estéticas cada vez mais antropomórficas. Esta tese, longamente desenvolvida por Hegel em sua Filosofia da Arte, é apenas esboçada na Fenomenologia. Aqui nos interessa apenas apresentar brevemente alguns momentos fundamentais desta evolução indicados no capítulo sobre a religião da arte, os quais correspondem a importantes figuras da arte, da escultura ao teatro.

É interessante observar que a obra de arte plástica - especificamente: a escultura clássica do deus olímpico - é descrita na Estética como o paradigma 
do fenômeno do belo, enquanto na Fenomenologia ela serve muito mais para pontuar o fenômeno religioso do ritual de adoração e devoção circunscrito no espaço do templo, que também envolve duas outras formas de manifestações artísticas: a arquitetura e a música, ou, mais especificamente, o canto devocional. A escultura é aqui situada no centro do templo, como uma espécie de nascimento da espiritualidade concreta da obra em sua aparência já antropomorfizada, que reflete a própria subjetividade do artista. A escultura do deus ou o fenômeno estético do deus esculpido deve ser compreendido, portanto, neste conjunto, a partir da diferenciação entre uma forma de trabalho ainda artesanal e o trabalho espiritual do artista propriamente dito.

\section{2 - Do simbolismo da religião natural como produto do trabalho do artesão à beleza da religião da arte}

No parágrafo da Fenomenologia intitulado “A Religião Natural”, Hegel trata da forma de religião que corresponde na Estética à forma de arte simbólica. Assim, ele descreve a manifestação do espírito nesta forma de religião como o que ele chama de artesão (Werkmeister). O artesão é menos do que o verdadeiro artista, exatamente porque seu trabalho - embora corresponda à essência do trabalho em geral, na medida em que "se produz a si mesmo como objeto" é, ao contrário do verdadeiro trabalho artístico, "um trabalho instintivo", comparável àquilo que "as abelhas" fazem quando "constroem (bauen) seus favos". Este trabalho artesanal de transformação da matéria sensível em uma forma que mantém ainda o predomínio do aspecto desta materialidade imediata tem como paradigma as obras arquitetônicas orientais antigas, tais como as pirâmides e os obeliscos.

Esse tipo de obra, resultante de um trabalho inconsciente do espírito, semelhante ao engenhoso arquitetar das abelhas, é considerado por Hegel como ainda vazio de espírito, ou melhor: como obra que "ainda não está, nela mesma, preenchida (erfüllt) pelo espírito". Esta descrição da obra artesanal corresponde, com algumas importantes diferenças, à análise que Hegel irá realizar em sua Filosofia da Arte sobre a obra de arte simbólica, cuja significação ou espírito permanece na superfície da exterioridade, ou (o que acaba sendo o mesmo) na profundidade inacessível de uma obscura interioridade, que, para ser decifrada, depende sempre de uma interpretação que lhe dê sentido, tal como o símbolo carece sempre de ser interpretado.

Mas a exterioridade presente na obra do artesão se dá também enquanto divisão entre matéria e forma, ou entre o ser-em-si material e o ser-para-si ideal da consciência-de-si que trabalha. A ausência de espírito na obra a 
transforma em um objeto abstraído da atividade espiritual que o formou, sendo ainda reduzido a uma espécie de adorno decorativo. Contudo, mesmo a obra arquitetônica tende a evoluir de seus primitivos traços retilíneos para formas mais complexas, que mimetizam a natureza viva ou orgânica. A arquitetura passa, assim, a incluir em suas formas originalmente inorgânicas e essencialmente minerais referências miméticas das formas naturais das plantas e dos animais. Esta passagem do inorgânico ao orgânico prepara na verdade o processo de reconhecimento do $\mathrm{Si}$ do artesão em sua própria obra. No mimetismo da forma animal, presente na arquitetura simbólica, na forma, por exemplo, da expressão dos hieróglifos, a arquitetura mimetiza, sobretudo, o processo de produção inerente a esta forma de ser, e com isso faz referência ainda que de modo indireto - ao processo produtivo que caracteriza a própria criação do trabalho do arquiteto ou do artesão.

A obra arquitetônica atingirá seu grau mais elevado de espiritualidade na forma do templo, que abriga não mais a obscuridade labiríntica das tumbas mortuárias que tinham por objetivo atingir o infinito por meio da conservação da materialidade do corpo já sem vida, mas sim a vivacidade do culto às divindades imortais, que transitam no mundo dos homens mortais e penetram sua alma durante a comemoração das festas rituais, assim como o vinho e o pão penetram e nutrem seus corpos extasiados. Na verdade, este cenário típico dos cultos pagãos da religião antiga dos gregos permite que Hegel denomine esta forma de religião em sua Fenomenologia do Espírito como religião da arte, seguindo ainda bastante de perto a denominação presente em seus primeiros escritos de "religião bela" ou "religião para povos livres". Naquela época, a intenção de Hegel era classificar este tipo de religiosidade como superior à forma das religiões judaica e cristã, por julgar ambas como religiões "positivas", ou seja, religiões que, ao longo de seu processo de institucionalização, foram perdendo a espiritualidade e dando lugar a ritos exteriores e objetivos. $\mathrm{Na}$ Fenomenologia, Hegel, ao contrário, interpreta o cristianismo já como religião revelada, exatamente por considerar fundamental a efetivação do processo, iniciado na religião grega, de antropomorfização da divindade. O cristianismo espiritualiza o que resta de naturalidade na religião grega, e transforma, por exemplo, o pão e o vinho do culto pagão a Baco e a Ceres em corpo e sangue de Cristo.

A permanência da naturalidade ou sensibilidade na religiosidade grega antiga é, entretanto, exatamente o que possibilita a sua beleza ou o seu aspecto essencialmente artístico. O templo grego é, ao mesmo tempo, a morada do deus esculpido e o espaço do gozo dos homens que o freqüentam. 
A escultura do deus grego, sua forma plenamente humana e, ao mesmo tempo, idealmente bela, realiza, segundo Hegel, a própria essência da divindade, que, neste mesmo capítulo da Fenomenologia intitulado "A Religião da Arte", ele define como sendo "a unidade do ser-aí universal da natureza e do espírito consciente-de-si, que em sua efetividade se manifesta contrapondo-se ao primeiro". ${ }^{8}$ A naturalidade da divindade grega, expressa de forma mais perfeita na escultura clássica, é contudo, como observa Hegel, já inteiramente suspensa (no sentido de afgehoben), completamente idealizada, pois que a natureza é totalmente transformada em obra de arte, ou — para usar a expressão presente na Fenomenologia — "o ser-aí universal da natureza é nessa unidade o elemento refletido no espírito, a natureza transfigurada pelo pensamento, unida com a vida consciente-de-si",

A estátua, entretanto, possui um caráter estático que gera uma contradição imanente entre seu conteúdo eterno e sua matéria exageradamente sensível e perecível. A forma humana, resposta para a síntese ideal da beleza que será minuciosamente valorizada na Estética, é aqui apenas valorizada na medida mesma do resultado do processo de reconhecimento espiritual do artista em sua obra e mediante sua obra. Na Fenomenologia, ao contrário de elevar a escultura do deus antropomórfico ao nível da máxima realização da beleza, Hegel preocupa-se em estabelecer para esta manifestação artística tão estática e tão concreta um contraponto ao mesmo tempo dinâmico e cuja materialidade seja contrariamente sutil e evanescente; e o encontra no fenômeno da música, do canto devocional, presente no culto às divindades. A importância desta manifestação estética em relação dialética com o fenômeno da escultura é também a capacidade de elevar a alma por meio de um mergulho em sua própria interioridade. Se diante da escultura o devoto experiencia a sensação da presença exterior e concreta do deus, pelo canto, ele, ao contrário, se volta para o interior de si, ao mesmo tempo que se eleva, transcendendo o próprio espaço do templo, promovendo aquilo que Hegel denomina de purificação da alma. Este processo de interiorização, presente no culto, já aponta para a transformação do templo ou da morada divina da exterioridade arquitetônica em interioridade da própria consciência de si. Hegel descreve poeticamente este processo de interiorização no interior da própria religião da arte:

(...) do culto procede a consciência-de-si satisfeita em sua essência, e o deus se aloja nela como em sua morada. Essa morada é para si a noite da substância, ou a pura

8 Cf. HEGEL, G. W. F. Fenomenologia do Espírito. Trad. de Paulo Meneses. Petrópolis: Vozes, 1990. Parte II, p. 160. (A seguir, citada apenas como Fenomenologia).

9 Idem. 
individualidade da substância; porém já não é a tensa individualidade do artista, que ainda não se reconciliou com sua essência que se torna objetiva, mas é a noite tranquiilizada, que sem nada ter falta, tem nela o seu "pathos" porque retorno da contemplação, [ou] da objetividade suprassumida (aufgehoben). Esse "pathos" é, para si, a essência do raiar-do-sol mas [que] de agora em diante declinou dentro de si: e tem em si mesmo seu ocaso - a consciência-de-si — e com isso ser-aí e efetividade. ${ }^{10}$

Essa unidade entre o objetivo e o subjetivo efetivado no culto, ainda sob a forma de uma "certeza objetiva" ou "certeza gozosa" de deus, é também descrita por Hegel na Fenomenologia como o mistério próprio do místico, o mistério da transubstanciação de uma substância que ainda não atingiu a sua verdadeira universalidade, o mistério do êxtase e do entusiasmo do ritual báquico, cuja embriaguez precisa, segundo Hegel, "acalmar-se" exatamente na obra de arte que lhe serve de contraponto, na objetividade e na estaticidade da escultura do deus. Há, contudo, uma síntese entre estes dois pólos de manifestações artísticoreligiosas, entre a calma estática da imagem esculpida do deus antropomórfico e a dinâmica do entusiasmo dionisíaco gerado pela embriaguez de vinho, música e dança. Trata-se da transformação deste ritual em um fenômeno verdadeiramente artístico: o teatro. No teatro, a bela corporeidade da estátua ganha a dinâmica do corpo vivo do ator que encarna sua personagem, e a embriaguez dionisíaca inconsciente dá lugar à clareza apolínea da poesia. De fato, a verdadeira síntese resultante da dialética presente no culto pagão da bela religião é, como observa Hegel, o próprio fenômeno da linguagem e, mais especificamente, da linguagem em sua forma propriamente estética - a linguagem poética:

O elemento perfeito em que tanto a interioridade é exterior, como a exterioridade é interior, é a linguagem; mas não é a linguagem do oráculo, de todo contingente e singular em seu conteúdo; nem o hino, ainda emocional e louvando somente o deus singular; nem o balbuciar carente-de-conteúdo, do frenesi báquico. ${ }^{11}$

O oráculo é, de fato, uma espécie de protótipo da linguagem poética, é o início de um processo que vai da imaginação natural até a clareza objetiva da poesia épica, culminando na tragédia grega em sua representação no teatro. Mas é exatamente nesta última e mais requintada forma de manifestação estética do espírito grego que será também representado poeticamente o oráculo. O herói trágico, como Antígona ou Édipo, busca integrar seu saber com sua ação, mas sua busca de autoconhecimento é ainda representada por sua consulta ao oráculo. O oráculo é, assim, o grande emblema dessa forma de eticidade imediata. 


\section{3 - Da necessidade do oráculo à subjetividade concreta do ator de teatro}

Como Hegel esclarece na Fenomenologia do Espírito, o oráculo é "a linguagem própria do deus, que é o espírito do povo ético". Na medida, entretanto, em que a eticidade dos gregos é ainda algo imediato e que a subjetividade não atingiu um nível suficiente de interioridade e reflexão, a verdade universal expressa pelo oráculo é ainda recebida como uma "língua estranha" ou como a "língua de uma consciência estranha", ${ }^{12}$ como uma linguagem ainda não clara. Entretanto, Hegel enfatiza, nesta passagem, que o grau de contingência da determinação de uma ação por meio do oráculo não difere daquele de uma determinação fundada tão-somente em uma individualidade particular arbitrária: “(...) o contingente é o irrefletido e estranho; e a consciência ética se deixa também assim determinar quanto a isso de uma maneira irrefletida e estranha, como por meio de um jogo de dados." 13

Não uma subjetividade abstrata e contingente, mas uma subjetividade concreta poderá suprassumir efetivamente essa determinação ainda exterior do oráculo, que é também denominada por Hegel na Fenomenologia como "obra de arte abstrata". Em sua Filosofia da História, Hegel mostra claramente os limites da democracia e da eticidade grega, na qual é permitida, por exemplo, a escravidão, na medida em que a subjetividade e a autoconsciência se vêem restritas a apenas determinados indivíduos. Os gregos não possuem ainda, em sua imediatidade ética, uma forma de subjetividade, como a "consciência moral" (Gewissen), ou a moralidade. Sua eticidade e sua liberdade consistem apenas em seguir o ethos ou o costume de viver para o todo, sem que o indivíduo se isole em um processo de auto-reflexão de uma vontade subjetiva. ${ }^{14}$ Essa eticidade imediata, que define a chamada democracia grega, comporta, por isso, perfeitamente, a prática do oráculo, como suprimento para a ausência de uma vontade particular subjetiva:

Os oráculos estão ligados à democracia, tal como ela existia na Grécia. Faz parte do decidir a partir de si mesmo uma subjetividade concreta da vontade, a qual é determinada por motivos preponderantes. Os gregos ainda não tinham essa força da mesma. (...) Com a evolução da democracia, nós vemos como, em situações importantes, os oráculos não são mais consultados, mas as opiniões singulares dos representantes do povo se fazem valer e são decisivas. ${ }^{15}$

12 HEGEL. Fenomenologia, v. II, p. 163.

13 Ibidem, p. 164.

14 Cf. Hegel, G. W. F. Vorlesungen über die Philosophie der Geschichte. In: Hegel, G. W. F. Werke. Frankfurt am Main: Surkamp, 1986. p. 308. v. 12.

15 Ibidem, p. 310 et seq. 
Este avançar da democracia grega, na forma da participação efetiva dos cidadãos em um panteon, se dá concomitantemente ao desenvolvimento da produção artística como "obra de arte espiritual", que inicia o processo de retorno da essência divina na autoconsciência. Para Hegel, é primeiro a poesia quem vai, como obra essencialmente espiritual, não apenas explicar o natural, mas realizar concretamente o conteúdo divino, como subjetividade consciente de si. Pois a arte inicia o processo de autoconsciência do espírito, na medida em que a obra de arte, e, mais especificamente, a poesia, é a linguagem não mais alheia ou contingente, mas como "o verdadeiro ser-aí consciente-de-si". ${ }^{16}$ Esta consciência se inicia no momento do reconhecimento de que o divino é conteúdo, e portanto resultado, da própria criação poética.

A arte trata do espírito em sua existência concreta, seja ela como individualidade imaginada ou representada objetivamente pela figura do herói, seja como individualidade imaginante do poeta. Estes dois extremos correspondem exatamente à evolução própria do espírito - descrita por Hegel principalmente na Fenomenologia do Espírito - em direção ao saber de si mesmo, ou seja: à subjetividade livre.

$\mathrm{O}$ verdadeiro momento de síntese entre estes dois momentos se realiza no teatro, na medida em que o ator recria a criação do poeta, ao mesmo tempo que incorpora o caráter do personagem representado, apesar da aparência imediata de sua própria personalidade. Hegel, que era comprovadamente um grande amante do teatro, reconhece a atuação do ator como uma arte à parte:

É o herói mesmo quem fala, e a representação mostra ao ouvinte - que ao mesmo tempo é espectador - homens conscientes-de-si, que sabem e sabem dizer seu direito e seu fim; a força e a vontade de sua determinidade. São eles artistas que não exprimem o exterior de suas decisões e empreendimentos de modo inconsciente, natural e ingênuo, como [o faz] a linguagem que acompanha na vida efetiva o agir rotineiro; mas exteriorizam a essência interior, demonstram o direito de seu agir; afirmam refletidamente e exprimem determinadamente, em sua individualidade universal, o "pathos" a que pertencem, - livre das circunstâncias casuais e do particularismo das personalidades.

O ser-aí destes caracteres são enfim homens efetivos, que assumem os personagens dos heróis, e os apresentam em linguagem efetiva, - não narrativa, mas própria. ${ }^{17}$

Na principal obra filosófica de Hegel, a que descreve com a linguagem filosófica do conceito a epopéia absoluta do espírito e enfatiza exatamente a 
efetividade ou a fenomenalidade deste espírito no mundo e na história, nenhuma outra obra de arte, a não ser o teatro, poderia ocupar o lugar de síntese, exatamente porque o teatro é o fenômeno estético de efetivação não apenas da poesia, mas também da pintura, da música e da escultura. Todos transformados em uma viva unidade que repete a própria vida de forma ideal. Na Estética, esta síntese se dá em muitos momentos, mas o teatro é sempre descrito como fim de um movimento de efetivação da individualidade autoconsciente.

Em sua Filosofia da Arte Hegel irá desenvolver esta idéia, caracterizando o teatro moderno como o fenômeno estético no qual se dá a efetivação da liberdade subjetiva, iniciada na tragédia grega. Esta última representa, entretanto, a perda de um parâmetro de unificação entre o indivíduo e a substância ética. Na modernidade, a eticidade foi totalmente substituída pela moralidade. A ação trágica moderna incorre, muitas vezes, na pura contingência do acaso, não mais na certeza de uma necessidade ética. Contudo, a perda desta necessidade ética transformou o indivíduo moderno em um sujeito livre, um sujeito que se encontra sozinho com sua própria consciência-de-si, sem deuses e sem templos, apenas sob o céu aberto e sobre o solo de sua própria vontade subjetiva. A imagem do templo em ruínas, que cerca o ator do teatro moderno, é utilizada poeticamente por Hegel em sua Filosofia da Arte para caracterizar esta nova forma de subjetividade modena. Uma subjetividade que perdeu a máscara que a aproximou um dia da divindade encarnada na estátua. Uma subjetividade que perdeu o pano de fundo de uma substância ética representada na Antigüidade pelo coro trágico, uma subjetividade cuja principal tragédia e cujo principal destino é a solidão de sua própria liberdade. 